\title{
Crafting decision options and alternatives for designing cultural observation system using general morphological modelling
}

\author{
Jaber Moghaddampour ${ }^{a^{*}}$, Farhad Darvishi Setalani ${ }^{\mathbf{b}}$, Hakem Ghasemi ${ }^{\mathrm{b}}$ and Mohammad \\ Rahim Eivazi ${ }^{\mathrm{c}}$
}

${ }^{a}$ Ph.D Candidate in Futures Studies, Imam Khomeini International University, Iran

${ }^{b}$ Associate professor of Imam Khomeini International University, Iran

${ }^{c}$ Professor of Shahed University, Iran

\section{H R O N I C L E}

\begin{tabular}{l}
\hline Article history: \\
Received October 28, 2017 \\
Received in revised format: \\
January 8, 2017 \\
Accepted March 2, 2018 \\
Available online \\
March 2, 2018 \\
\hline Keywords: \\
Solution space \\
Decision making \\
Model \\
General Morphological Analysis \\
(GMA) \\
Horizon scanning \\
Observation
\end{tabular}

\section{A B S T R A C T}

According to connoisseurs, cultural system is encountering a fully new space in future decades and cultural indicators will be exposed by some dangers; for the same reason, cultural observation activities in management dialogue of Iran are emphasized; the concept of "observation" in Iran is facing with challenges including being far from the concepts of futures studies and the focus on "cultural indicators monitoring" while cultural engineering needs foresight and identification of affecting progressive and deterring factors on the culture. The present study aims at providing alternatives to design an observation system by considering the monitoring and scanning simultaneously to bring out strategic and futurist vision for cultural organizations. To this end, the solution space and morphological field of observation (parameters and values) by using MA/Carma Viewer software package is designed based on the literature review and forming a five-member expert group and specialized conversations. Upon Internal Consistency Assessment of parameters and by considering some values as drivers, Parameters Activity Check was conducted to study the reactions by other parameters and values. After sense-making and proper understanding of the model behavior, an Inference and "What-If" model were devised; some configurations were studied and provided in order to aware a part of proper alternatives for designing a cultural observation system (two scenarios). Scenario selection is different due to contingencies and conditions of executing the process as well as the users' needs and goals in cultural observation system and cultural organizations can make decisions and design detailed observation systems by using morphological models, solution space and alternatives provided in the present study and depended on their goals and needs.

\section{Introduction}

According to a group of futurists, in 2020 and beyond, the world will be cultural and global competitions will be changed from economic - military to cultural ones (Azimi, 2011). Considering complexities and expansion of globalization in today's competitive world, those countries that have no

\footnotetext{
* Corresponding author.

E-mail address: jabermp@gmail.com (J. Moghaddampour)

(C) 2018 by the authors; licensee Growing Science, Canada. doi: $10.5267 /$ j.dsl.2018.3.001
} 
target and plan for their culture will be get out of the scene by other cultures (Royayi \& Rasooli, 2008). According to connoisseurs, cultural system is encountering a fully new apace in future decades and cultural indicators in Islamic Republic of Iran will be exposed by some dangers; to the same reason, cultural observation activities in management (Zare et al., 2014). For the same reason, such concepts as cultural observations are raised in cultural management dialogue of I. R. of Iran which is introduced as an introduction for cultural engineering (Kaynejad, 2006). Realizing such important goal needs timely initiatives on cultural issues and it is necessary to monitor affecting progressing and deterring factors on culture in order to conduct modifications, changes and policymaking on-time.

The concept of "observation" in I. R. of Iran is facing with challenges including being far from the concepts of futures studies and being limited to "observe culture status quo" in activities called "cultural observation"; such concept is emerged from futurism basics. However, there are turbulences in current status while observation concept is the naturally emanated from futures studies and it seems necessary to use more proper concepts of futures studies. Considering the conceptual turbulence in theory and limitation of cultural observation activities to cultural observation and being far from the concepts of futures studies, crafting options for designing observation system in which the concepts of scanning and futures studies including horizon scanning and its components are regarded is necessary in order to pave the way for effectiveness of activities by cultural organizations.

\section{Research purpose}

Considering abovementioned explanations, Present study aims at providing alternatives for an observation system bring out strategic and futurist vision for cultural organizations. By morphological analysis, such system provides options based its parameters and values which indicate paths and alternatives for cultural observation. Based on major goal, minor ones are as below:

- Cultural observation definition by emphasis on the concept of scanning and monitoring and considering cultural context.

- Recognizing parameters (dimensions) and values (conditions) of cultural observation to achieve cultural observation morphological field.

- Analyzing the consistency of parameters and values in order to represent alternatives of cultural observation morphological model based on target parameters

\section{Methodology}

To provide alternatives for cultural observation system, morphological method is used; morphology is the study of the shape and arrangement of parts of an object, and how these parts "conform" to create a whole or Gestalt. The "objects" in question can be physical objects (e.g. an organism, an anatomy, a geography or an ecology) or mental objects (e.g. word forms, concepts or systems of ideas) (Ritchey, 2002). Recently, morphological analysis is used by some authors in USA and Europe in futures studies field; likewise, morphology is also used in designing horizon scanning systems; for instance, Connery (2012) utilized horizon scanning for Australian National Security Policymaking. Morphological analysis is a generalized method for structuring and analyzing complex problem fields that are inherently non-quantifiable and cannot be causally modelled or simulated and require a judgmental approach. Its pioneer is Fritz Zwicky $(1966,1969)$ in California Institute of Technology in 1930s and 1940s. Morphological analysis relies on a constructed parameter space, linked by way of logical relationships, rather than on causal relationships and a hierarchal structure (Ritchey, 2006). The approach begins by identifying and defining the parameters (or dimensions) of the problem complex to be investigated, and assigning each parameter a range of relevant "values" or conditions. Together, these make up the variables or parameters of the problem to be structured (Ritchey, 2013). Morphology should be process-oriented and group-oriented; a small group of subject experts is required which 
should not be more than 5 to 7 members. Under ideal conditions, the group should be heterogeneous to represent other aspects of the issue (Ritchey, 2002).

A morphological field is created by locating parameters against each other in parallel columns which shape an n-dimensional matrix; each cell of n-dimensional cox consists of a special value or condition for each parameter. A special solution or situation for a set of problems is designed by selecting the value of each parameter. A morphological analysis for 6 to 10 parameters can have 50,000 to 5,000,000 configurations. Thus, it is important to reduce the total set of (formally) possible configurations in the problem space to a possibly smaller set of internally consistent configurations representing a "solution space."

Such important result is achieved through investigating internal relations of parameters and eliminating conflicted values and cross-consistency assessment. CCA is based upon the insight that there may be numerous pairs of conditions in the morphological field which are mutually incompatible.there is no reference here to causality or direction, but only to (mutual) consistency. All values of parameters are compared by cross-consistency effects. Each pair of values are studied and judges to find out to what extent compared pairs can be meaningful along each other and shows a consistent relationship (Ritchey, 2013). There is no reference here to causality or direction, but only to (mutual) consistency. There are three types of inconsistencies involved here: purely logical contradictions (i.e. those based on the nature of the concepts involved); empirical inconsistencies (i.e. relationships judged to be highly improbable or implausible on empirical grounds), and normative constraints (e.g. relationships ruled out on e.g. ethical or political grounds).

Note, nevertheless, that it is essential not to let normative judgments initially influence the crossconsistency assessment. For this particular reason, it is possible to only let logical and empirical judgements be made initially. Although normative judgements can, and often must, be made, they must never be confused with logical and empirical considerations. We must first investigate what is possible, before making judgements about what is, and what is not, desirable.

By identifying the inconsistencies of parameters' values, a few numbers of options may be provided. A special solution or situation for a set of problems is designed by selecting the value of each parameter; when solution space is analyzed, resulted morphological model will be a flexible inference model ("what-if") in which some parameters can be considered as inputs and outputs and each parameter can be seen as a driver or independent variable and each value can be an input or output (Ritchey, 2013).

In the present research, cultural observation morphological analysis (acquiring parameters and values) is conducted by morphology technique after literature review and forming a five-member expert group and specialized conversations. Noteworthy, morphological analysis is executed by using MA/Carma Viewer and under the backup of scientific researches by postgraduates.

\section{Literature review}

Plebańczyk (2014) asserts that in responding cultural demands and problems, many countries have established what is called "cultural observatories" or "cultural laboratories" and there are many entities recognized as cultural observatory or laboratory. In his research, Plebańczyk (2014) represented and compared different models and goals of observatories. Their objectives, scopes and forms were different. According to Plebańczyk (2014) any effort to discuss on cultural observatories is full of remarkable risks. It is due to the fact that it is too difficult to categorize clearly what helps or does not help to determine an observatory since today observatories conduct broad activities not only on culture analysis but also on their transformations. One can say that scanning and monitoring are parts of activities conducted by cultural observatories. Futurists are always looking for recognizing even the weakest signals of change. These signals show that what new development and trends are on the way 
and possibly the future is facing with which events. Overall, those efforts which imply discovering changes and developments are called observation (Malekifar, 2007). Observation is a tool to aid policymakers for developing and retaining their needed foresight that is the key activities include scanning (horizon and environment) and monitoring). Activities and contents of the conducted studies on cultural observation especially in I. R. of Iran have considered more weight for monitoring and status quo and a futurist attitude and using the concepts of futures studies are not considered. Although in Iranian cultural observation recipe, futures studies and foresight concepts are pointed out to somehow, what is seen theoretically and practically in Iranian cultural management dialogue is the lack of a well-established process and lack of attention to observation concepts in futures studies in activities called cultural observation; overall, two key activities namely "scanning" and "monitoring" are important in cultural observation.

\subsection{Scanning (horizon and environment)}

Usually, scanning is referred to regular and repetitive observations of an environment aimed at recognizing and identifying those phenomena which need more precise investigations for some reasons (Van Rij, 2010a). There are many definitions on horizon scanning.

For more than a decade, one of the most recent definitions include: "Horizon Scanning is the systematic outlook to detect early signs of potentially important developments. These can be weak (or early) signals, trends, wild cards or other developments, persistent problems, risks and threats, including matters at the margins of current thinking that challenge past assumptions" (Cuhls et al., 2015). It seeks to determine what is constant, what may change, and what is constantly changing in the time horizon under analysis (Cuhls et al., 2015). Draeger (2011) believes that horizon scanning and environmental scanning are apparently interchangeable and even futurists are often in doubt on how to use them. As a scanner, he asserts that it seems there are differences between them; environmental scanning means to look for what is happening with immediate outcomes while horizon scanning is wider searches on possible outcomes of what is happening and it is to look for weak signals to understand how these may change in future. Environmental scanning is to identify and study issues related to "the topic of concern" systematically which are not necessarily emerging or unexpected issues and it may focus on a short term interval. Horizon scanning usually emphasizes on phenomena with novel features. However, it should not be said that horizon scanning is always looking for unknown or uncertain issues. Types of issues usually considered in horizon scanning will pass through the filters of an environmental scanning process. Anyhow, horizon scanning should reveal unknown unknowns (Miles \& Saritas, 2012).

\subsubsection{Elements of horizon scanning}

Overall, it is important to realize that decisions about the definition of units do guide what futurerelevant observations will be submitted (Könnölä et al., 2012). By studying relevant literature and definitions, the most important elements which should be respected in observation are expounded below.

\subsubsection{Weak signals}

Weak signals are important early signs of change emergence (Amanatidou et al., 2012). Early signs on changes are possible by not proved which may be converted into remarkable indicators for important factors like developments, threats and innovations. They are early signs which show shift paradigm, future trends, drivers and discontinuities (Kuosa, 2010). As a raw material of foresight weak signals can be considered as unstructured, minor and incomplete environmental data which may be refined by considering the context and its valuable information and, in addition, may bring strategic and applied knowledge (Mendonca et al., 2012). 


\subsubsection{Trends and Drivers}

Trends can be defined as the general direction of relative predictability in a certain period. Trends can be long term with strong effect (mega trend) and short term with lower effect. Trends may be a part of issue or the reason of an issue (Van Rij, 2013). Drivers refer to those forces, factors and uncertainties admirable by stakeholders and can create or drive changes. In fact, change drivers are those factors, forces, events or developments which can be acceptable towards a strategic selection change, investment, R\&D or strategies and foresight knowledge. They are acceptable currently and will be valuable in future (Saritas \& Smith, 2011).

\subsubsection{Discontinuous and wildcards}

Potential changes in the external environment identified by horizon scanning can be either continuous or discontinuous. The most disruptive type of discontinuous change is low-probability but high-impact events, referred to in the futures literature as wild cards (Bengston, 2013). Wild cards represent the occurrence of a singular (historically original), sudden (abrupt, fast), surprising (unexpected) and shattering (serious, severe) event that come out of the blue and therefore present a significant foresight challenge both for policy makers and researchers (Mendonca et al., 2009). Discontinuous refers to rapid and important changes paths without radical unpredictability or depth surprise. Discontinuous is ongoing situation-impact overtime and beyond independent events, have rapid changes and change past paths infrastructural and expected policies and planning systems (Saritas \& Smith, 2011).

\subsubsection{Emerging issues}

Emerging issues usually describe a future narrative or mini scenario which should be considered by policymakers and society (Amanatidou et al., 2012). Emerging issues are fact based future storylines that either envisage "promising" developments and events or "threatening" developments and events which need support and fostering and/or countervailing and adaptive measures (Van Rij, 2013). They point out opportunities, threats and problems which need political initiatives. These initiatives may conduct not only institutional amendments but also monitoring or prioritizing initiatives such as financing or regulating a research program of or starting innovations. The poser of the issue is defined by the combination of facts, interests and emotions (Van Rij, 2011).

\subsubsection{Discourse and Hypes}

Sense-making or socialization of emerging issues is a key action to analyze observation information in which future dialogues are shaped by a workshop on future issues or specialized dialogues with actors (Cuhls et al., 2015). In fact, describing the issues should not only refer to trustable scientific and real findings but also should have expectable impact on important value systems, interests, power relations and emotions; dialogues on emerging issues refer to communicative discussions on emerging issues happened in political arena or a decision making process (Amanatidou et al., 2012). The term hype generally refers to over-enthusiasm, excessive publicity around a certain topic, excessive advertising or making exaggerated claims (Van Rij, 2013). The aim of hypos is to influence on dialogue on a strong manner albeit in short term. Identified emerging issues in the political discourse can only be successful if the storyline that is used is communicatively strong in the context of the political discourse and preferably connects to the present day political discourse (Amanatidou et al., 2012).

\subsubsection{Uncertainties and scenarios}

One can use observation information to develop scenarios about the future, which can lead to "strategic conversations" about likely threats and opportunities (Connery, 2012). In the simplest way, uncertainty is emanated from lack of information or lack of analysis and thinking. Scenarios pave the way to control 
uncertainties. A set of scenarios should be sufficiently complicated so that they can cover most relevant aspects of environmental uncertainty. Early warning addresses to early identification of change sigs, trends and trends stoppage in relation to scenario. To this end, it is better to identify a number of indicators; that is, changes in environment which increase or decrease the possibility of each scenario occurrence (Lindgren \& Bandhold, 2003).

\subsubsection{Persistent Problems and Issues}

The main problem is the gap between status quo and standard and desired conditions. If any deviation from standard status is observed, they are revealed as problems and warnings in observation process; more persistent and stable issues are valuable and may relate to unexpected or neglected phenomena. For a persistent issue it is not so uncommon to change its nature in its long term evolution. A good approach is to ask what might lead to trends being accelerated, decelerated, or transformed. But there are also things that are so familiar that we do not question their persistence and stability (Miles \& Saritas, 2012).

\subsection{Monitoring}

Monitoring issues will help for the identification of warning problems. Surveillance of those problems will then be accomplished through sufficient models and related indicators. Monitoring would provide to the needed data collection defined by relevant models and indicators. Monitoring an issue and surveillance on a problem may start with choosing signs of new and emerging issues. If we start exploring an issue - even in the loosest way - we require to have an - even minimal - idea. What happens is that we unconsciously depend on a cognitive model which is implicit. In fact, for horizon scanning, we apply more than one model even if it is too deficient. Scanning has its own roots in a model which is implicit improved and refined through the process of analysis. Both horizon scanning and monitoring are similar. Their difference, here, resides actually in the sophistication of the model used, not in the actual process utilized to do scanning and monitoring. Hence, scanning and monitoring can utilize most often the same of tool or support. However, the difference is that when gathering signals through a scan that aims at identifying emerging meta-issues and issues, monitoring of an issue and surveillance of a problem may also pick upon signals of novel issues emerging (Lavoix, 2012).

\subsection{Horizon scanning approaches and techniques}

Exploratory; an exploratory approach identifies different types of signs by an open search profile. In an exploratory profile, signs are detected by applying an open search profile. Information provided by this exploratory scanning is rich and without any definitive focus. In this approach, without a clear framework with emergent potential issues in mid, the author searches for information on new development. In exploratory approach, emergent issues are detected by processing information through various resources. The aim of the exploratory scanning approach is to identify a long list of signals that are precursors for emerging issues, only demarcated by the policy domain selected (Amanatidou et al., 2012).

Issue-Centered; this approach is concentrated on core documents (primary signals) which describes important parts of potential issues. In this approach, issues preliminary description is recognized as the basis of potential signals which can support or do not support real emergence of an issue. In present approach, scanning is focused on those signals that have a complete or important narrative of future for a certain level of policies. Issue-oriented approach identifies those signals that support future storylines for policies and usually include completely focused processes which highlight an issue which is apt to high influence and needs an action at the time being. Issue-centered scanning does not predict issues . Rather it provides tools to alert for potential impact-rich issues that need policy attention (Amanatidou et al., 2012). To confirm emergent issues, secondary signals should be constantly monitored. Lavoix 
(2012) believes that the beginning of monitoring process is the selection of emergent issue signals. Overall, based on degree of participation and degree of automation, one can create three proper combinations of methods which lead into a full investigation of total observation process. These three combinations are explained below. The first combination can be seen more toward exploratory approach while the next two combinations are more issue-centered (Amanatidou et al., 2012).

- Twitter/wiki scanning which is complemented by processing of weak signals.(Participatory Semi automated)

- Focused expert review which is complemented by text-mining.(Non-participatory Semi automated)

- Focused expert review which is assisted by experts'survey, literature review and attending conferences (Combined-Manual).

Utilizing such techniques based on policymakers; needed information should be consisted of techniques or combination of techniques which can cover all different steps of observation actions.

\subsection{Culture}

In order to enter cultural observation discussion, we address to culture concept and its elements and components since one cannot talk about cultural observation without proper understanding the culture and its components. To this end, it is necessary to consider the opinions of different thinkers on culture in order to use them to expound culture nature. Although the concept of culture has various definitions and interpretations like many other concepts in human sciences and integrating them in cone transparent and thorough definition is not possible easily, Borofsky asserts that efforts to define culture are like attempts to acquire wind. This involves attractive metaphor on cultural changing nature and emphasizes that it is too hard to take care on the meaning of this term (Kavoosi et al 2008).

\subsubsection{Cultural elements}

Thinkers have provided different levels, layers and elements to clarify culture concept. By aggregating and analyzing the views, one can say that concerning culture elements, thinkers point out three common elements: "basic assumptions", "behavioral value, traditions and paradigms" and "symbols and artifacts". Since each provided element by thinkers emphasizes on one (material or spiritual) aspect of culture, one can classify their verdicts so that elements on "basic assumptions" and "behavioral values, traditions and paradigm" are inside "culture spiritual aspect" while "symbols and artifacts" are inside "culture material aspect."

The manifests of culture (symbols and artifacts) include all phenomena seen, heard and touched by someone like physical environment architecture, language, technology and its products, Artistic creations, clothing styles, legends, storylines, etc. Behavioral values, traditions and paradigms indicate priorities or what should be done; according to Schein (2004), "basic assumptions constitute the core of culture; such assumptions are considered unnegotiable and if someone does not respect them, he/she is considered as incapable and is discarded". On this basis, as the main culture policymaking authority, Iranian Cultural Revolution Higher Council, culture in the Islamic Republic of Iran includes three elements of "basic assumptions", stable and rooted behavioral values, traditions and paradigms" and "symbols and artifacts" which can be defined in different levels of culture.

\subsubsection{Culture levels}

Culture levels mean studied and manageable level of culture which cover whole or remarkable part of culture. Culture level refers to a degree by which culture phenomenon can be identifiable for observer. In Iranian culture engineering map, it is pointed out that culture is identified, studied, analyzed and 
planned in three level of "National culture (Islamic-Iranian)", "Public Culture" and "Professional Culture".

National culture; It is system-type of basic assumptions, stable and rooted behavioral values, traditions and paradigms, symbols and artifacts of Iranian Muslim population (mainly in national borders created and stabilized within centuries and millenniums and gives identity to nation. Islamic-Iranian culture is the same excellent Islamic culture aspired in the Culture of Iran and is developed and revolved proportionate to history, geography, religion, language, etc. (Cultural Engineering Map of I. R. of Iran, 2013).

Public culture; a behavioral system of beliefs, values, insights, tendencies and symbols and artifacts which shape cultural general and common space of the society in certain intervals. Public culture emphasizes on life and behavioral values, tendencies and paradigms of the society and its depth and sustainability is lower than a national (Islamic - Iranian culture). Public culture is remarkable followed by temporal and spatial contingencies of the society and reflects the performance of other systems like cultural, social, political, judicial, cultural and other systems (Cultural engineering Map of the Islamic Republic of Iran, 2013). Public culture is what people are involved in their daily life from how to wear clothes to etiquette and driving, respecting the rights of neighbors, protecting local natural resources and green lands, resecting children's education to empathy with needy people in both local/regional and international levels, religious traditions, social tradition to behavior in streets and stadiums all are covered by public culture (Shaffer, 2012).

Professional culture; a system of behavioral beliefs, values and paradigms and the symbols of incumbents of each profession. Professional cultural values are achieved through long years of specialized training or experience and long term job learning. Professional culture of policymakers, physicians, marketers, teachers, judges, militarists and religious clerks are, inter alia, examples of such culture,

\subsubsection{Cultural monitoring}

As mentioned before, monitoring is conducted based on proper models and indicators. One can say that for good cultural observation, cultural issues should be recognized and classified well. Since cultural observation in Iran should be performed based on a local paradigm and should be affected by dominating climate over society (Moqtadaei, 2008), cultural components and, as a consequence, cultural indicators which should be monitored are impacted Iranian ideal cultural features. On the other hand, considering the relationship between culture and other aspects of the society, cultural developments can root in different environments (political, economic, etc.). In fact, different environments can involve signs which influence on culture (Eivazi, 2015). Therefore, cultural issues should be classified based on the level of culture (national, public, professional), and elements of culture (assumptions, values, norms, symbols and artifacts) and society context (culture, economy, politics, security, society, etc.).

In his research, Anbari (2011) considered four religious, civil, national and rational aspects in I. R. of Iran. His research is conducted by focusing on cultural observation and his classification is closer to cultural monitoring. One can say that his classification is the most complete one on cultural issues and indicators in the field of culture monitoring in Iran. According to him, culture multiple aspects include "ethical and religious", "normative and common", "civil and interactive", "identity and historic (national)", "material and technological", "administrative and political" and "cognitive" aspects and if we intend to combine all seven aspects, we can determine four religious, civil, national and rational aspects in culture. Thus, one can say that culture in I. R. of Iran the consolidation of religion, nationality, civilization and rational/scientific insights. Religious aspect indicates ethical and religious indicators in culture as well as valued, propensity and religious behaviors. Civilization involves normal, 
interactive and administrative aspects of culture; culture civil aspects represent dominating rules for humans' collective life. Identity, historic and common aspects of any culture are inside its national subsets and cognitive, material and technological aspects indicate the level rationality of the culture. Rational aspects show society's attitude toward the world, enjoyments and hard nesses in daily life and, overall, dominating spirit over daily economic and political actions. In this section, culture capabilities to accept science and technology in removing initial and economic needs are recognized. Overall, one can say that culture system in Iran is shaped by three elements: "basic assumptions", behavioral stable and rooted values, traditions and paradigms" and "symbols and artifacts". Each element has components based on its ideal culture which can be devised by "different culture levels (national, public and professional)" and "context of the society". Monitoring culture components is based on proper metrics and its main goal is to find the situation of culture components through measuring formulated metrics for them.

In cultural monitoring, emergent issues and scenarios are also important; concerning cultural emergent issues, one can monitor secondary signals to devise effective policies and initiatives after confirming emergent issues. Likewise, another product of cultural observation is cultural scenario devised by analyzing signs and cultural drivers and identifying uncertainties. For cultural scenarios, some indicators are determined and by monitoring them, realization or non-realization of scenarios are pursued to adopt proactive strategies and policies on them.

Cultural indicators monitoring has brought a passive approach since it reveals problems in order to adopt proper policies.

Monitoring secondary signals of emergent issues and scenarios guiding metrics is an active approach in facing with cultural problems, opportunities and threats; in fact, by monitoring guiding signs and indicators, it will be acted proactively against possible changes of culture indicators which may cause the emergence of new culture, culture change or culture decadence.

\subsubsection{Cultural organizations}

Realization cultural goals and programs of any country require efficient administrative organs and entities. Without efficient and effective organizations, it will be impossible to execute any program, albeit planned in the best way. Based on well-devised in law, goals and functions Cultural organizations in Iran are categorized in three groups: "policymaking organizations, "executing organizations" and "monitoring organizations". Likewise, one can supplement such categorization by two criteria and achieve another categorization by integrating different criteria; does culture shape goal and direction of its activities (culture - oriented and non-culture oriented?) Do their audiences are a special class of society or whole society (general and particular?)

Based on above criteria, one can identify 12 cultural organizations of which six ones are "culturecentered organizations ${ }^{1}$ (Salehi Amiri \& Azimi Dolatabadi, 2008). According to cultural observation issue which consists of both cultural monitoring and scanning and the relationship between discussions on futures studies and observation with policymaking, the audiences of present study are culturecentered organizations that are responsible for monitoring the culture in Iran and have both public and particular audiences; in fact, such organizations can be seen as the users of "cultural observation morphological model" to perform relevant tasks in this scope and are provided in present study.

\footnotetext{
${ }^{1}$ Culture-centered policymaking organization with public audiences; culture-centered policymaking organizations with particular audiences; culturecentered executing organizations with public audiences; culture-centered executing organizations with particular audiences; culture-centered observer organizations with public audiences; culture-centered observer organizations with particular audiences
} 


\section{Cultural observation definition}

Overall, two key activities namely "scanning the signs and identifying cultural emerging issues" and "monitoring and identifying problems in culture components and indicators" are important in cultural observation. On this basis and based on provided materials on the concept of observation and culture, one should consider below points in defining cultural observation and its morphological field:

- In cultural observation term, observation explains the process and the way to do a job while cultural refers to "observation scope" and explains "observation components and cultural indicators.

- Culture is imagined in "national", "public" and professional levels.

- Culture has three elements: "basic assumptions", "stable and rooted behavioral values, traditions and paradigms" and "symbols and artifacts".

- Culture interacts with other aspects of social system including politics, economy, etc.

- Monitoring is based on implicit and scanning is based on explicit models.

- Considering culture interaction with other aspects of the society, signs of potentially important Cultural developments can be scanned in different environments (political, economic, etc.).

- Scanning focuses on identifying early signs of potential developments including weak signals, trends, drivers, discontinues, wildcards, emerging issues and other developments which are at the margins of current thinking and planning and not restricted to those.

- Monitoring culture components and elements can be conducted separately; likewise, monitoring can use the outcomes of scanning process. In fact, monitoring is based on secondary signals and scenario indicators as well as the indicators of culture components.

- Cultural observation be seen as a tool for Cultural Policy-Making and also part of a Foresight Process in culture field.

- Scanning yields to proactive policies and initiatives for emerging issues while monitoring leads to finding the problems and policymaking for problem solution.

Considering above points, cultural observation is defined as below:

"Systematic scanning and examination of important signs of cultural potential developments in different environments and describing cultural emerging issues and identifying likely potential opportunities and threats; monitoring "basic assumptions", "stable and rooted behavioral values, traditions and paradigms" and "symbols and artifacts" and finding cultural problems in the level of national, public and professional culture based on cultural components and indicators; likewise, monitoring the indicators of cultural scenarios and secondary signals to identify cultural emerging issues (progressing and deterring) timely which in surveyed time horizon supports cultural policymaking and foresight.

\subsection{Cultural observation parameters and values}

Cultural observation parameters are classified in two groups of "form" and "content and function" parameters based on morphology and by literature review and forming expert group and specialized discussions considering Iranian local environment.

Acquired parameters represent what users and decision makers in cultural observation system should consider. To provide a comprehensive coverage of each parameter in cultural observation, relevant values for each parameter is identified. Functional parameters provide expected purpose, context and outcomes of cultural observation and "form" parameters and options to execute cultural observation process. Values for each parameter are selected by the aim of awareness on proper options to design 
cultural observation system and it means that options are choose by process execution requirements and conditions by users and policymakers. Cultural observation morphological field is outlined in Table 1. Parameters and their values are clarified below.

\subsubsection{Content and function parameters}

Parameter "A" shows morphological field of culture levels. According to Iranian cultural engineering map (2013), culture consists of three levels including "national culture (Islamic - Iranian)", "pubic culture" and "professional culture" which possess the relevant values. The elements of culture system are parameter "B". As already discussed, it includes "basic assumptions", "stable and rooted behavioral values, traditions and paradigms" and "symbols and artifacts". Since the scope of cultural observation includes all social systems fields like economy, culture, politics, society and so on (anonymous, 2005), parameter " $\mathrm{C}$ " is a context in which cultural observation should consider interaction and impacts of other dimensions (Rashad, 2006). The values of this parameter includes "culture", "politics", "economy" and "society". In a social system, culture interacts with other areas such as politics, economy and society and cultural observation cannot be a limited process in culture and it has mutual relations with other dimensions of the society (Negahdary, 2006). Considering cultural interaction with other dimensions of the society, cultural observation should consider different environments to monitor cultural development signs. Parameter " $D$ " represents the values of "cultural observation dimensions and components" in two "signs of potentially important Cultural developments" and "cultural components and indicators". Considering culture interaction with other dimensions through literature review, the values of this parameter in cultural development signs section consists of weak signals, trends, drivers, discontinuous, trends, wildcards and problems. Likewise, cultural components and indicators section includes four religious, national, civil and rational values (Anbary, 20111). Overall, in research literature, key uncertainties, emerging issues, political challenges, supplying information needs (Cuhls et al., 2015) and providing information to a varied range of stakeholders (Van Rij, 2010a), reports and summaries of policies and scenarios (Habegger, 2009) are mentioned as observation products. According to Cannery (2012), some people use observation to develop scenarios on future which can lead into "strategic dialogues" on likely threats and opportunities. Meanwhile, emerging issues bring opportunities and threats (Van Rij, 2013). Therefore, opportunities and threats can be seen as products of observation. Considering above points, one can consider "Products or Outputs" parameter on morphological field including "Emerging Cultural Issues", "Cultural threats and Opportunities", "Uncertainties and cultural scenarios" and "Database and Required Reports". The final parameter is on cultural observation function. For observation activities, foresight functions (anonymous, 2005; Van Rij, 2010a; Habegger, 2009; Bishop, 2009; Bengston, 2013); decision making (Van Der Heijden, 2011; Butter et al., 2010; Konnola et al., 2012; Bengston, 2013; Sutherland et al., 2011; Van Rij, 2010a, 2010b; Lesca \& Lesca, 2014); nd policymaking (ananymous, 2005; Amanatidou et al., 2012; Habegger, 2009, Van Rij, 2010a, 2010b; Saritas \& Miles, 2012) are mentioned. Therefore, one can say that two main functions of cultural observation are supporting "cultural foresight" and cultural decision making and policymaking". Parameter "E" shows mentioned values in the format of "backup function".

\subsubsection{Form parameters}

Considering backup functions, cultural observation can be seen as a part of a foresight cycle (Miles \& Saritas, 2012; Major et al., 2001; Bishop, 2009) and as an independent activity and tool of policymaking (Habegger, 2009; Aguilar, 1967; Choo, 2001; Da Costa et al., 2008). Parameter "E" refers to the relevant values of backup function under "modus of operandi" title. Parameter " $F$ " expresses main steps of cultural observation. Main phases of cultural observation can include "monitoring" and "scanning" mentioned in parameter " $\mathrm{F}$ ". "The scope of scanning" is another parameter; based on relevant purposes and current options in content parameters including levels, elements, components, context of observation activities can for a scope of three values of "broad", "focused or narrow" and 
"configuration"; in fact, the scope of scanning can consider focusing on a special field and information limited search and/or "thorough, fully open and exploratory" to achieve an overview (Cuhls et al., 2015; Bengston, 2013) and their configuration. Issue oriented and exploratory approaches form the values of tenth morphological field values. Considering the concept and needs, observation include both the rather passive mode of looking at information (viewing) and the more active mode of looking for information (searching) (Habegger, 2009). To this end, there are two separate exploratory and issue oriented approaches which can shape observation process basis (Amanatidou et al., 2012). Scanning is the process of searching for emerging trends and issues and should include a balance of exploratory scanning and exploitation scanning (Bengston, 2013). As the main steps of cultural observation, scanning and monitoring can be "continnuous", "periodic" and "ad hoc (based on needs and request) and irregular" (Habegger, 2009; Connery, 2012; Bengston, 2013). Values of parameter "K" are located under the title of "frequency". Time horizon is another parameter of cultural observation morphological field. Observation time horizon depends on purposes and frequency as well as different scanning and monitoring phases. In fact, providing observation outputs can be done by "long term" (Habegger, 2009; Cuhls et al., 2015; Babbage, 2008), mid-term (Habegger, 2009; Cuhls et al., 2015) and short term (Cuhls et al., 2015) and "multiple" (Bengston, 2013) situations. The values of "resource" parameter are in three groups including "human resources (e.g. utilizing experts' networks), textual source (e.g. newspapers, books and articles), and online source (e.g. internet and online databases). Depended on surveyed issue and environment, on can use proper resources (Hiltunen, 2008). For "general methods of cultural observation method", one can imagine three positions: "Participatory-Semi automated", "Non participatory-Semi automated" and "Combined-Manual". The first configuration can be seen further in line with exploratory approach while the next two configurations are further issue-oriented (Amanatidou et al., 2012). Finally, parameter "O" is on User / Responsible organization of cultural observation which, based on provided explanations in previous sections, has two "Culture-centered politician organization" and "Culture-centered observer organization" values.

\section{Table 1}

Cultural observation morphological system field (crafting options: parameters and values)

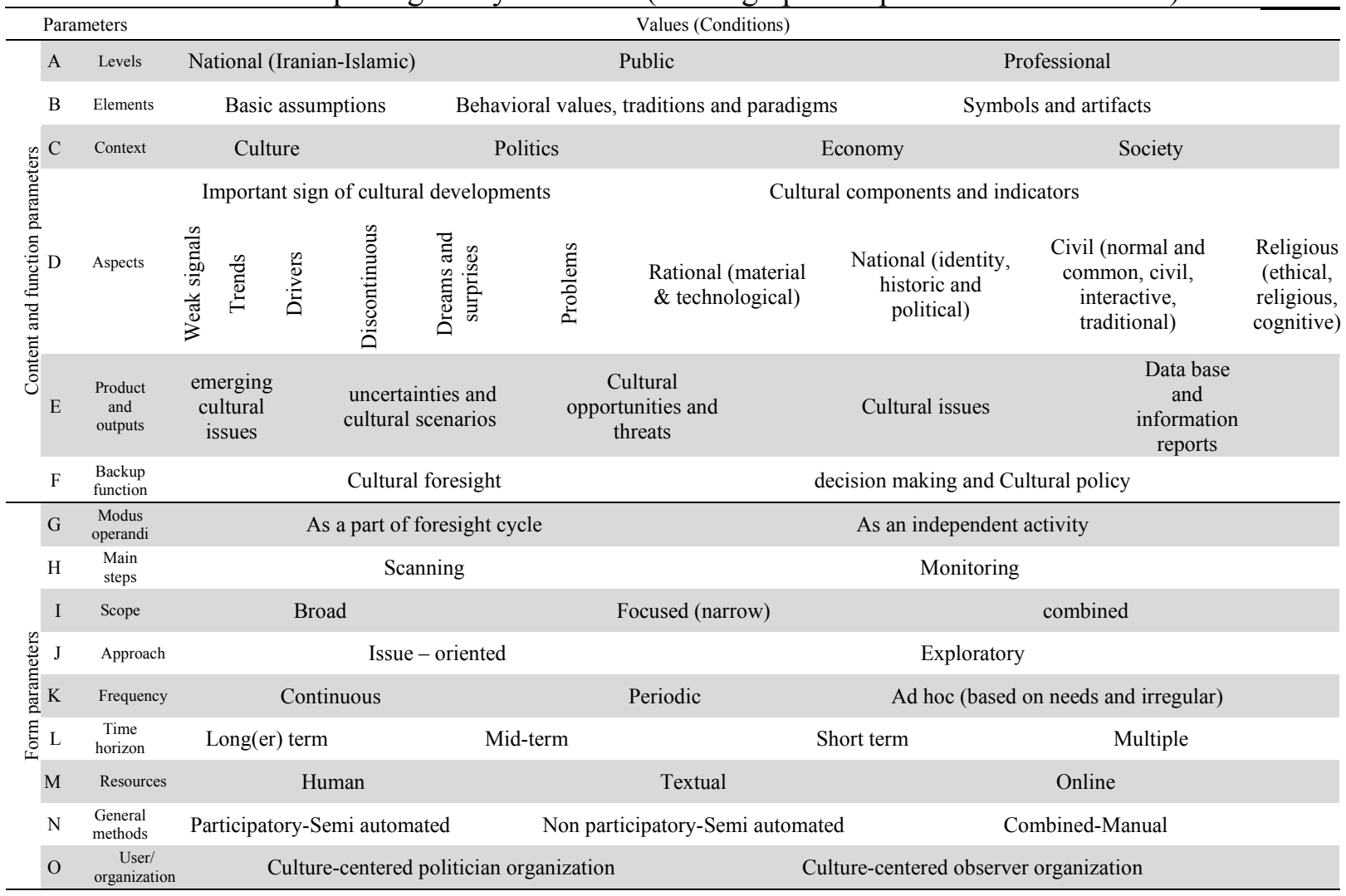




\section{Morphological analysis and solution space}

\subsection{Identifying connected parameters}

In General Morphological Analysis (GMA), the Cross-Consistency Assessment (CCA) serves as a check on the integrity and clarity of the concepts being employed, and allows us to identify and weed out all internally incompatible relationships in order to reduce the total problem space of the morphological field to a smaller, internally consistent solution space. With computer support this solution space can be treated as an inference model (Rictchey, 2015). Begin with parameter connectivity, since this needs to be established for a parameter pair before we can start the internal consistency assessment. We say that two parameters in a morphological field are "connected" if they directly impose constraints on one another, such that one or more pairs of values in their respective value ranges are incompatible. It might seem that the best way to establish parameter connectivity is to simply go through the whole CC-matrix and determine these all at once, i.e. before starting any specific internal consistency assessments. And in certain special cases this is true, for instance if the model is very large and one needs to make certain assumptions in order to save time. In present study, the number of parameters $(\mathrm{N}=15)$ and concerning their values, the simple configurations (by selecting the value of each parameter will more 3.7 million; therefore, to reduce solution space and to focus on monitoring and scanning, the connection among parameters were studied and unconnected parameters were identified. Although the paths of final model can be considered with other parameters without any conflict, by consistency assessment, one can recognize parameters, level parameters, elements, context, scope, frequency and resources connected or unconnected to other parameters. Table 2 outlines the connection of parameters for cultural observation morphology (green blocks).

Table 2

The relations of parameters: connected parameters on morphological cultural observation field (green blocks)

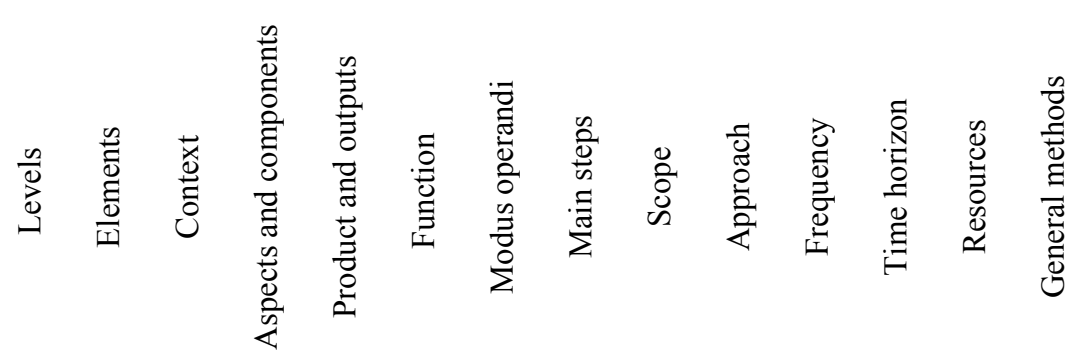

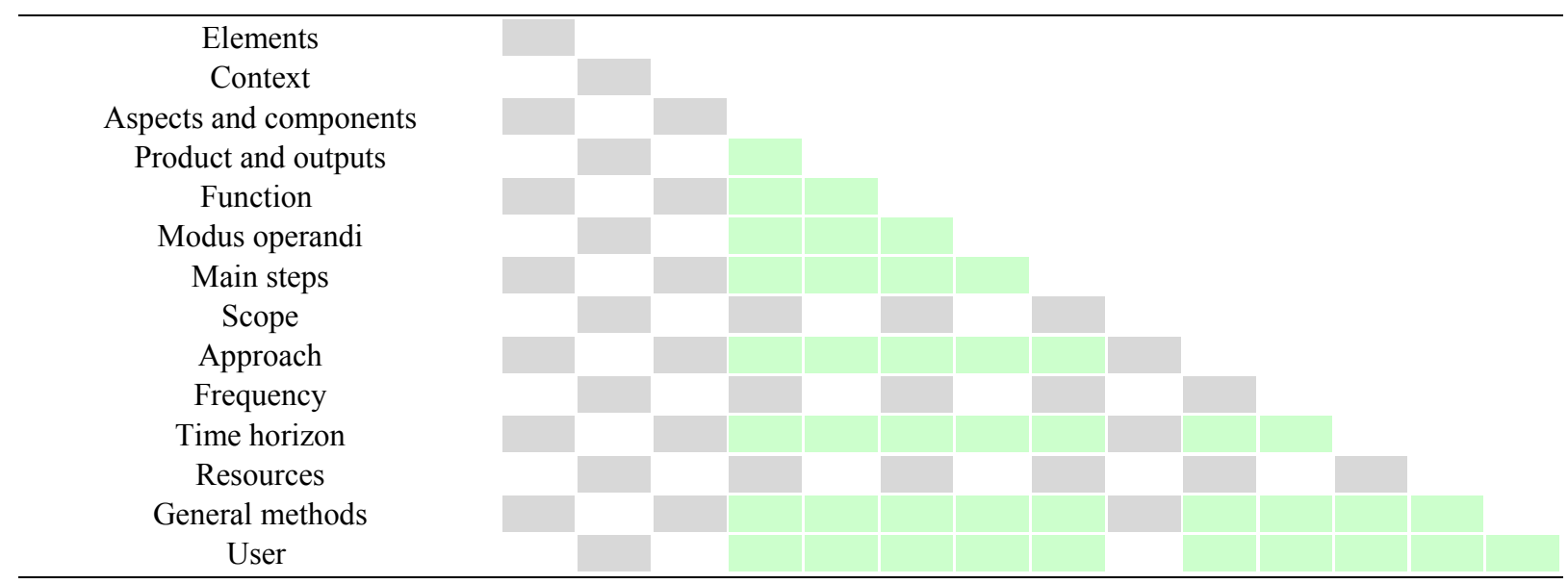




\subsection{Internal consistency assessment}

By parameters consistency assessment, major parameters are recognized which should be studied in cultural observation system. For internal consistency assessment, connected parameters are inserted into software (Fig. 1). Although other parameters are important, to reduce analysis complexity and focusing on limited solution space, the concentration of connected parameters are considered which does not mean to eliminate other parameters from solution space; by emphasis on connected parameters, properties of morphological field are shown in Table 3.

\section{Table 3}

The properties of cultural observation system morphological field by considering connected parameters

\begin{tabular}{|c|c|c|c|}
\hline $\begin{array}{c}\text { Number of parameters } \\
\mathrm{N}\end{array}$ & $\begin{array}{c}\text { Number of dyadic relationships } \\
\text { between parameters } \\
\text { (\# parameters blocks) } \\
1 / 2 \mathrm{~N}(\mathrm{~N}-1)\end{array}$ & $\begin{array}{l}\text { Number of CCM cells } \\
\sum_{i=1}^{n-1} \sum_{j=2}^{n} v_{i} \cdot v_{j}\end{array}$ & $\begin{array}{r}\begin{array}{r}\text { Number of simple } \\
\text { configurations }\end{array} \\
\prod_{t=1}^{n} V_{i}\end{array}$ \\
\hline 8 & 28 & 247 & 3840 \\
\hline
\end{tabular}

\begin{tabular}{|c|c|c|c|c|c|c|c|}
\hline \multicolumn{4}{|c|}{ 区E Carma CCA Viewer - [Jaber-2.scn] } & \multirow{2}{*}{\multicolumn{4}{|c|}{ - }} \\
\hline \multicolumn{4}{|c|}{ 国 File Edit Wiew Grid Options Window Help } & & & & \\
\hline \multicolumn{8}{|c|}{ 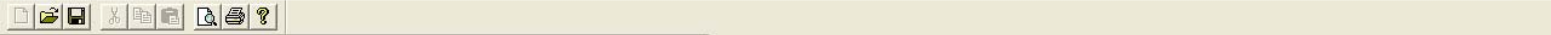 } \\
\hline \multicolumn{8}{|c|}{ 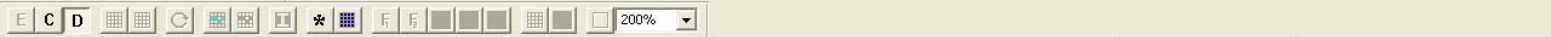 } \\
\hline Functions & $\begin{array}{l}\text { The main } \\
\text { steps }\end{array}$ & Approach & Components & $\begin{array}{l}\text { Time } \\
\text { horizon }\end{array}$ & General methods & $\begin{array}{l}\text { Products and } \\
\text { outputs }\end{array}$ & $\begin{array}{l}\text { User / Responsible } \\
\text { organization }\end{array}$ \\
\hline $\begin{array}{l}\text { Cultural } \\
\text { Foresight }\end{array}$ & Scanning & Exploratory & $\begin{array}{l}\text { Signs of Cultural } \\
\text { Developments }\end{array}$ & Long(er) term & $\begin{array}{l}\text { Participatory-Semi } \\
\text { automated }\end{array}$ & $\begin{array}{l}\text { Emerging } \\
\text { Cultural Issues }\end{array}$ & $\begin{array}{l}\text { Culture-centered } \\
\text { politician organization }\end{array}$ \\
\hline \begin{tabular}{|l|} 
Decision \\
making and \\
cultural policy
\end{tabular} & Monitoring & Issue-centered & $\begin{array}{l}\text { Cultural components } \\
\text { and indicators }\end{array}$ & Mid term & $\begin{array}{l}\text { Non } \\
\text { participatory-Semi } \\
\text { automated }\end{array}$ & $\begin{array}{l}\text { Uncertainties } \\
\text { and cultural } \\
\text { scenarios }\end{array}$ & $\begin{array}{l}\text { Culture-centered } \\
\text { observer organization }\end{array}$ \\
\hline $\begin{array}{l}\text { As part of a } \\
\text { foresight } \\
\text { cycle }\end{array}$ & & & & Short term & Combined-Manual & $\begin{array}{l}\text { Cultural } \\
\text { opportunities } \\
\text { and threats }\end{array}$ & \\
\hline \multirow{2}{*}{$\begin{array}{l}\text { As an } \\
\text { independent } \\
\text { activity }\end{array}$} & & & & Multiple & & $\begin{array}{l}\text { Cultural issues } \\
\text { I problems }\end{array}$ & \\
\hline & & & & & & $\begin{array}{l}\text { Database and } \\
\text { Required } \\
\text { Reports }\end{array}$ & \\
\hline
\end{tabular}

Fig. 1. connected parameters in MA/Carma-Viewer software package

In most cases - and especially in working with open-ended, exploratory problem complexes (which is what GMA is particularly suited for) - it is operationally more practical to determine connectedness in conjunction with the internal consistency assessment of each parameter block. Upon reducing solution space and studying connection of parameters, internal consistency assessment is performed for values of connected parameters. Normally, for the types of problems that we treat with GMA, three levels of constraints will suffice. We can use the following three basic assessment keys :

- = Possible; what one would expect; good fit

$\mathrm{K}=$ Possible; but not optimal; on the boundary

$\mathrm{X}=$ Impossible 
Each of these can, in turn, be "typed", i.e. as formal, empirical or normative (Ritchey, 2015). Parameters internal consistency assessment by paired comparison of their values are inserted into software after specialized study by a five-member expert group (Fig. 2).

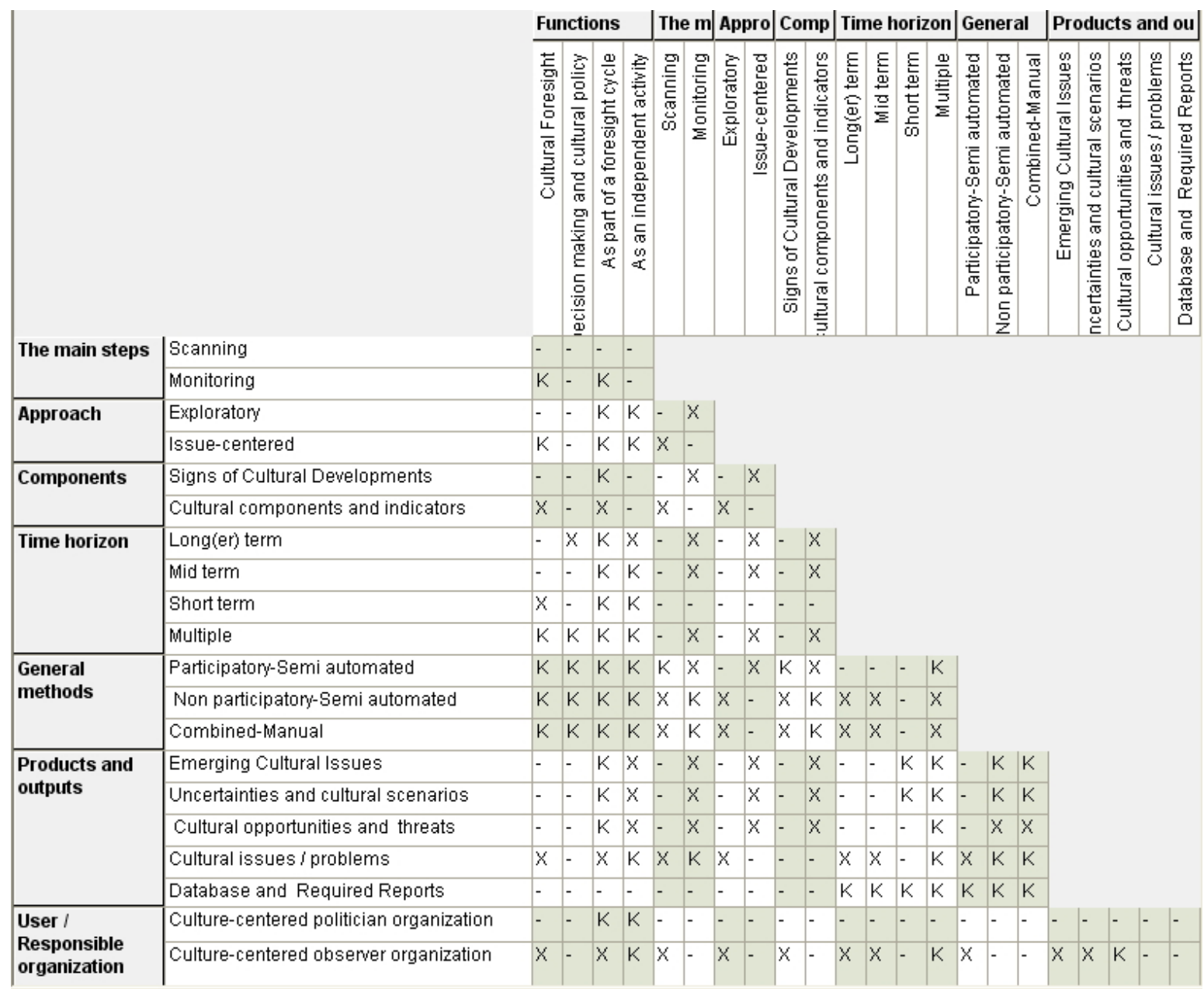

Fig. 2. cultural observation morphological field: connected parameters internal consistency assessment

\subsection{Cultural observation system solution space based on scanning and monitoring}

When the CCA has been completed properly. The Viewer will allow to run the model, designate different drivers and make "what if" inferences. This will give the flexibility to explore the solution space of morphological field, and present alternative solutions depending on different drivers or inputs (Ritchey, 2015). In present study, the output of software represented totally 59 configurations for the values of connected parameters in which at least one value for each parameter is shown in morphological model.

Considering the emphasis of present research on connected parameters and main steps which include scanning and monitoring, mentioned values are considered as drivers on which generated configurations are based. In fact, solution space of present study is a set of configurations in which scanning and monitoring are the main variables. In Fig. 3, "monitoring" and in Fig. 4, "monitoring" are considered as drivers in cultural observation morphological model. As seen, 46 of 59 configurations in solution space are connected to scanning driver and 13 configurations which involve the values of other parameters are connected to monitoring driver of main steps. Fig. 5 compares solution space based on scanning and monitoring drivers. Joint values in solution space are rendered in blue. 


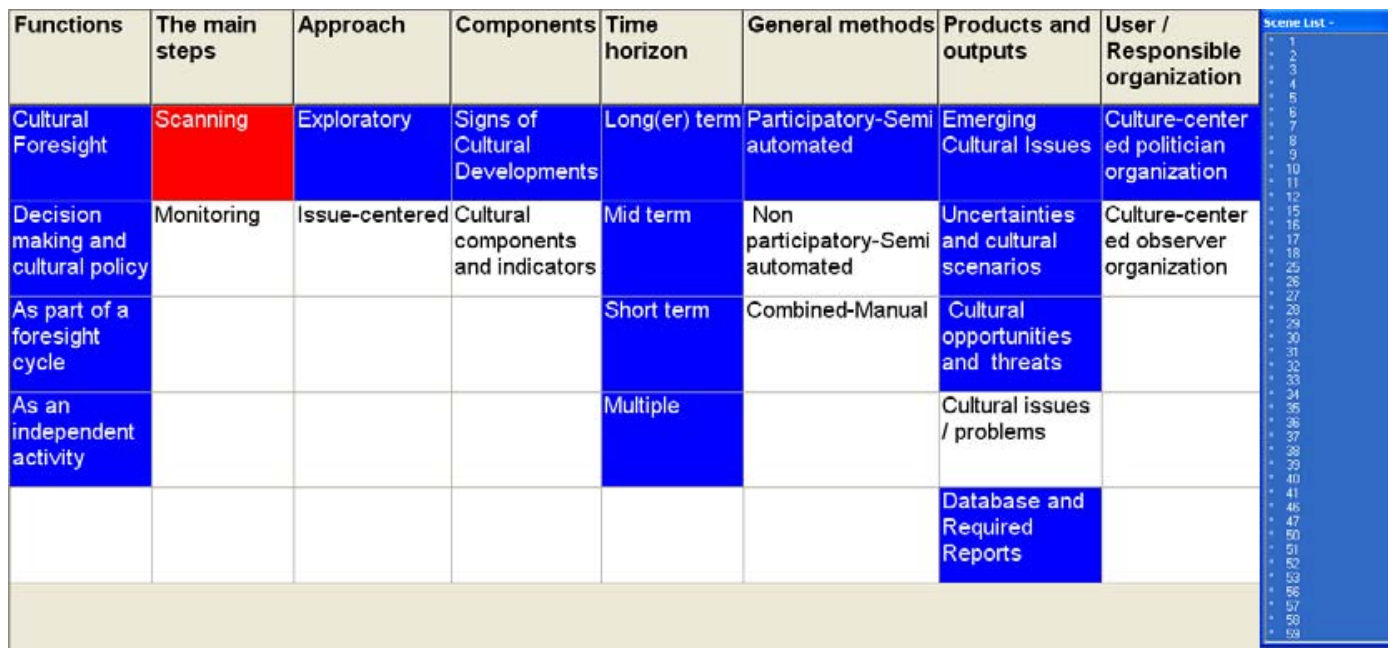

Fig. 3. Cultural observation solution space based on scanning driver

\begin{tabular}{|c|c|c|c|c|c|c|c|c|}
\hline Functions & $\begin{array}{l}\text { The main } \\
\text { steps }\end{array}$ & Approach & Components & $\begin{array}{l}\text { Time } \\
\text { horizon }\end{array}$ & General methods & $\begin{array}{l}\text { Products and } \\
\text { outputs }\end{array}$ & $\begin{array}{l}\text { User I } \\
\text { Responsible } \\
\text { organization }\end{array}$ & $\begin{array}{l}\text { Scene list - } \\
\vdots 13 \\
\vdots 14 \\
19 \\
20\end{array}$ \\
\hline $\begin{array}{l}\text { Cultural } \\
\text { Foresight }\end{array}$ & Scanning & Exploratory & $\begin{array}{l}\text { Signs of } \\
\text { Cultural } \\
\text { Developments }\end{array}$ & Long(er) term & $\begin{array}{l}\text { Participatory-Semi } \\
\text { automated }\end{array}$ & $\begin{array}{l}\text { Emerging } \\
\text { Cultural Issues }\end{array}$ & $\begin{array}{l}\text { Culture-center } \\
\text { ed politician } \\
\text { organization }\end{array}$ & 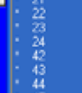 \\
\hline $\begin{array}{l}\text { Decision } \\
\text { making and } \\
\text { cultural policy }\end{array}$ & Monitoring & Issue-centered & $\begin{array}{l}\text { Cultural } \\
\text { components } \\
\text { and indicators }\end{array}$ & Mid term & $\begin{array}{l}\text { Non } \\
\text { participatory-Semi } \\
\text { automated }\end{array}$ & $\begin{array}{l}\text { Uncertainties } \\
\text { and cultural } \\
\text { scenarios }\end{array}$ & $\begin{array}{l}\text { Culture-center } \\
\text { ed observer } \\
\text { organization }\end{array}$ & {$\left[\begin{array}{l}40 \\
: 19 \\
: 54 \\
5\end{array}\right.$} \\
\hline $\begin{array}{l}\text { As part of a } \\
\text { foresight } \\
\text { cycle }\end{array}$ & & & & Short term & Combined-Manual & $\begin{array}{l}\text { Cultural } \\
\text { opportunities } \\
\text { and threats }\end{array}$ & & \\
\hline $\begin{array}{l}\text { As an } \\
\text { independent } \\
\text { activity }\end{array}$ & & & & Multiple & & $\begin{array}{l}\text { Cultural issues } \\
\text { / problems }\end{array}$ & & \\
\hline & & & & & & $\begin{array}{l}\text { Database and } \\
\text { Required } \\
\text { Reports }\end{array}$ & & \\
\hline
\end{tabular}

Fig. 4. Cultural observation solution space based on monitoring driver

\begin{tabular}{|c|c|c|c|c|c|c|c|}
\hline Functions & $\begin{array}{l}\text { The main } \\
\text { steps }\end{array}$ & Approach & Components & $\begin{array}{l}\text { Time } \\
\text { horizon }\end{array}$ & General methods & $\begin{array}{l}\text { Products and } \\
\text { outputs }\end{array}$ & $\begin{array}{l}\text { User / } \\
\text { Responsible } \\
\text { organization }\end{array}$ \\
\hline $\begin{array}{l}\text { Cultural } \\
\text { Foresight }\end{array}$ & Scanning & Exploratory & $\begin{array}{l}\text { Signs of } \\
\text { Cultural } \\
\text { Developments }\end{array}$ & Long(er) ter & $\begin{array}{l}\text { Participatory-Semi } \\
\text { automated }\end{array}$ & $\begin{array}{l}\text { Emerging } \\
\text { Cultural Issues }\end{array}$ & $\begin{array}{l}\text { Culture-center } \\
\text { ed politician } \\
\text { organization }\end{array}$ \\
\hline $\begin{array}{l}\text { Decision } \\
\text { making and } \\
\text { cultural policy }\end{array}$ & Monitoring & Issue-centered & $\begin{array}{l}\text { Cultural } \\
\text { components } \\
\text { and indicators }\end{array}$ & Mid term & $\begin{array}{l}\text { Non } \\
\text { participatory-Semi } \\
\text { automated }\end{array}$ & $\begin{array}{l}\text { Uncertainties } \\
\text { and cultural } \\
\text { scenarios }\end{array}$ & $\begin{array}{l}\text { Culture-center } \\
\text { ed observer } \\
\text { organization }\end{array}$ \\
\hline $\begin{array}{l}\text { As part of a } \\
\text { foresight } \\
\text { cycle }\end{array}$ & & & & Short term & Combined-Manual & $\begin{array}{l}\text { Cultural } \\
\text { opportunities } \\
\text { and threats }\end{array}$ & \\
\hline $\begin{array}{l}\text { As an } \\
\text { independent } \\
\text { activity }\end{array}$ & & & & Multiple & & $\begin{array}{l}\text { Cultural issues } \\
\text { / problems }\end{array}$ & \\
\hline & & & & & & $\begin{array}{l}\text { Database and } \\
\text { Required } \\
\text { Reports }\end{array}$ & \\
\hline
\end{tabular}

Fig. 5. comparing two configuration clusters for two drivers of main steps

\section{Conclusion and providing research findings}

Bringing strategic and forward-looking insights to cultural organizations and efforts to remove existing challenges (focusing observation activities on monitoring and getting far from futures studies concepts) upon reviewing literature on scanning concepts (environment and horizon) and monitoring, observation 
morphological field was provided by morphology and expert group's dialogues on designing and parameters key values needed for decision makers to design cultural observation system. For each parameter some values were identified to cover paths considered in cultural observation system thoroughly (Table 1).

Since there were over 3.7 million possible configurations, connected parameters were recognized (Fig. 1) by focusing on decision space and internal consistency assessment in order to avoid complexity (Fig. 2). Considering research problem and the necessity of emphasizing on scanning and monitoring, they were considered as drivers and two alternatives were created to conduct cultural organizations' observation with 46 and 13 solutions respectively (Figs. (3-5)). Generated morphological field would help to create an observation system needed by users through a fruitful tool for providing mentioned alternatives.

Noteworthy, selecting some values of parameters impact on the selection of values of some other parameters. The beginning of observation process requires decision depend on users' goals and expectations; one should decide on the level of observation (national, public, professional), elements of observation considered in observation (beliefs, values, norms, symbols and artifacts), the context of study, purposes and scope (broad, focused, combined), frequency (continuous, according to unconnected parameters and their provided values in cultural observation morphological field, periodic, need-based), resources selection (human, text, online). Selection of unconnected parameters has no impact on selecting the values of other values.

Selecting the values of connected parameters is particularly important in designing observation system; although choices are different depended on requirements and conditions of process execution as well as users' purposes and needs in cultural observation system.

To study final solution space (connected parameters and generating applied alternatives for Parameter Activity Check, the reaction of other parameters and values and the pursuit of inputs and outs were studied by considering single and multiple drivers and after sense-making of inputs and outputs and adequate feeling of model behavior, some configurations which show important values and configuration and new possibilities and confirmations of earlier expected results were selected; selected parameters for each parameters were selected by the aim of awareness of proper choices to design cultural observation system. as mentioned before, achieved morphological field upon internal consistency assessment of parameters is a deductive and "what if" model. On the same basis, by selecting some values as drivers, solutions and configurations close to expected results are studied and provided by considering Iranian local climate.

Before final study of observation morphological field, it is important that in a narrow sense, observation is a policy tool aims at structured collection of information and evidences on emerging issues, trends, developments, ideas and evens in a political, economic social, technological and ecological space. In a wider sense, it is used as a collective term for a multitude of so-called foresight activities that aim to improve the capabilities of organizations to deal with an uncertain and complex future (Habeggre, 2009). By such insight, observation is a part of strategic foresight and identifies inherent uncertainties to being prepare for future (Bishop, 2009) and shapes an important part of process comprehensive foresight to identify and collect evidences (Major et al., 2001). The first function is to inform policy by providing knowledge and new ideas that result in a tangible output such as reports, policy briefs, or scenarios about emerging issues and the second function paves the way for the potential benefits of horizon scanning and foresight. therefore, twofold: The traditional product-oriented focus on the "delivery of information on future developments as a basis for priority-setting" on the one hand ,and the focus on an innovative reflexive mutual learning process among policy-makers that stimulates "the emergence of common visions" on the other hand. Based on foresight, the second function expands the 
awareness of emerging issues and situations and supports strategic thinking by developing a range of possible ways of how the future could unfold (Habegger, 2009).

Considering above points and previous discussions, decision making on designing cultural observation systems will be based on below scenarios:

Scenario 1: In the case that cultural observation expected function is cultural foresight and as a part of foresight cycle, the culture-oriented policymaker organization should focus on scanning and utilize an exploratory approach to collect development signs. Public which is more appropriate for exploratory scanning includes semi-automatic contributive techniques. In such alternative, cultural policymaking organizations can start their foresight projects in surveyed time horizon, achieve such outputs as cultural emerging issues, uncertainties, cultural scenarios and cultural opportunities/threats by using data from observation in longer term, mid-term and short time horizon or a combination of them and provide the needed reports and applied databases (Fig. 6).

\begin{tabular}{|c|c|c|c|c|c|c|c|}
\hline Functions & $\begin{array}{l}\text { The main } \\
\text { steps }\end{array}$ & Approach & Components & $\begin{array}{l}\text { Time } \\
\text { horizon }\end{array}$ & General methods & $\begin{array}{l}\text { Products and } \\
\text { outputs }\end{array}$ & $\begin{array}{l}\text { User I } \\
\text { Responsible } \\
\text { organization }\end{array}$ \\
\hline $\begin{array}{l}\text { Decision } \\
\text { making and } \\
\text { cultural policy }\end{array}$ & Monitoring & Issue-centered & $\begin{array}{l}\text { Cultural } \\
\text { components } \\
\text { and indicators }\end{array}$ & Mid term & $\begin{array}{l}\text { Non } \\
\text { participatory-Semi } \\
\text { automated }\end{array}$ & $\begin{array}{l}\text { Uncertainties } \\
\text { and cultural } \\
\text { scenarios }\end{array}$ & $\begin{array}{l}\text { Culture-center } \\
\text { ed observer } \\
\text { organization }\end{array}$ \\
\hline $\begin{array}{l}\text { As part of a } \\
\text { foresight } \\
\text { cycle }\end{array}$ & & & & Short term & Combined-Manual & $\begin{array}{l}\text { Cultural } \\
\text { opportunities } \\
\text { and threats }\end{array}$ & \\
\hline $\begin{array}{l}\text { As an } \\
\text { independent } \\
\text { activity }\end{array}$ & & & & Multiple & & $\begin{array}{l}\text { Cultural issues } \\
\text { / problems }\end{array}$ & \\
\hline
\end{tabular}

Fig. 6. observation morphological model based on function parameter drivers

Scenario 2: In the case that expected function of cultural organization on observation is cultural decision making and policymaking, observation is seen as an independent activity and can focus on both monitoring and scanning (Fig. 7).

\begin{tabular}{|l|l|l|l|l|l|l|l|}
\hline Functions & $\begin{array}{l}\text { The main } \\
\text { steps }\end{array}$ & Approach & Components & $\begin{array}{l}\text { Time } \\
\text { horizon }\end{array}$ & General methods & $\begin{array}{l}\text { Products and } \\
\text { outputs }\end{array}$ & $\begin{array}{l}\text { User I } \\
\text { Responsible } \\
\text { organization }\end{array}$ \\
\hline $\begin{array}{l}\text { Cultural } \\
\text { Foresight }\end{array}$ & Scanning & Exploratory & $\begin{array}{l}\text { Signs of } \\
\text { Cultural } \\
\text { Developments }\end{array}$ & $\begin{array}{l}\text { Long(er) term Participatory-Semi } \\
\text { automated }\end{array}$ & $\begin{array}{l}\text { Emerging } \\
\text { Cultural Issues }\end{array}$ & $\begin{array}{l}\text { Culture-center } \\
\text { ed politician } \\
\text { organization }\end{array}$ \\
\hline $\begin{array}{l}\text { Decision } \\
\text { making and } \\
\text { cultural policy }\end{array}$ & Monitoring & Issue-centered $\begin{array}{l}\text { Cultural } \\
\text { components } \\
\text { and indicators }\end{array}$ & Mid term & $\begin{array}{l}\text { Non } \\
\text { participatory-Semi } \\
\text { automated }\end{array}$ & $\begin{array}{l}\text { Uncertainties } \\
\text { and cultural } \\
\text { scenarios }\end{array}$ & $\begin{array}{l}\text { Culture-center } \\
\text { ed observer } \\
\text { organization }\end{array}$ \\
\hline $\begin{array}{l}\text { As part of a } \\
\text { foresight } \\
\text { cycle }\end{array}$ & & Short term & Combined-Manual & $\begin{array}{l}\text { Cultural } \\
\text { opportunities } \\
\text { and threats }\end{array}$ \\
\hline $\begin{array}{l}\text { As an } \\
\text { independent } \\
\text { activity }\end{array}$ & & & & Multiple & & $\begin{array}{l}\text { Cultural issues } \\
\text { / problems }\end{array}$ \\
\hline
\end{tabular}

Fig.7 observation morphological model based on function parameter drivers 
Scenario 2.1: By focusing on scanning, responsible organization is a cultural policymaking organization and, like scenario 1, it can pursue cultural observation activities while the only difference is that most research projects are conducted in mid and long (or both) time horizons since the main function is cultural policymaking rather than foresight (Fig. 8).

\begin{tabular}{|c|c|c|c|c|c|c|c|}
\hline Functions & $\begin{array}{l}\text { The main } \\
\text { steps }\end{array}$ & Approach & Components & $\begin{array}{l}\text { Time } \\
\text { horizon }\end{array}$ & General methods & $\mid \begin{array}{l}\text { Products and } \\
\text { outputs }\end{array}$ & $\begin{array}{l}\text { User I } \\
\text { Responsible } \\
\text { organization }\end{array}$ \\
\hline \begin{tabular}{|l|} 
Cultural \\
Foresight
\end{tabular} & Scanning & Exploratory & $\begin{array}{l}\text { Signs of } \\
\text { Cultural } \\
\text { Developments }\end{array}$ & Long(er) term & $\begin{array}{l}\text { Participatory-Semi } \\
\text { automated }\end{array}$ & $\begin{array}{l}\text { Emerging } \\
\text { Cultural Issues }\end{array}$ & $\begin{array}{l}\text { Culture-cente } \\
\text { ed politician } \\
\text { organization }\end{array}$ \\
\hline $\begin{array}{l}\text { Decision } \\
\text { making and } \\
\text { cultural policy }\end{array}$ & Monitoring & Issue-centered & $\begin{array}{l}\text { Cultural } \\
\text { components } \\
\text { and indicators }\end{array}$ & Mid term & $\begin{array}{l}\text { Non } \\
\text { participatory-Semi } \\
\text { automated }\end{array}$ & $\begin{array}{l}\text { Uncertainties } \\
\text { and cultural } \\
\text { scenarios }\end{array}$ & $\begin{array}{l}\text { Culture-center } \\
\text { ed observer } \\
\text { organization }\end{array}$ \\
\hline $\begin{array}{l}\text { As part of a } \\
\text { foresight } \\
\text { cycle }\end{array}$ & & & & Short term & Combined-Manual & $\begin{array}{l}\text { Cultural } \\
\text { opportunities } \\
\text { and threats }\end{array}$ & \\
\hline \multirow[t]{2}{*}{$\begin{array}{l}\text { As an } \\
\text { independent } \\
\text { activity }\end{array}$} & & & & Multiple & & $\begin{array}{l}\text { Cultural issues } \\
\text { / problems }\end{array}$ & \\
\hline & & & & & & $\begin{array}{l}\text { Database and } \\
\text { Required } \\
\text { Reports }\end{array}$ & \\
\hline
\end{tabular}

Fig. 8. scenario 2.1: observation morphological model based on drivers of main step parameters (scanning)

Scenario 2.2: If observation system focuses on monitoring, culture-oriented policymaking organizations can monitor cultural components and indicators by adopting an issue-oriented approach. Considering an issue-oriented approach, used methods are overall non-contributive, semi-automatic or manual. Although in cultural monitoring, monitoring secondary signals, emerging issues and guiding indicators of scenarios is objective, monitoring in focused on short term and monitoring would yield to identify cultural issues (Fig. 9).

\begin{tabular}{|c|c|c|c|c|c|c|c|}
\hline Functions & $\begin{array}{l}\text { The main } \\
\text { steps }\end{array}$ & Approach & Components & $\begin{array}{l}\text { Time } \\
\text { horizon }\end{array}$ & General methods & $\begin{array}{l}\text { Products and } \\
\text { outputs }\end{array}$ & \begin{tabular}{|l|} 
User I \\
Responsible \\
organization
\end{tabular} \\
\hline $\begin{array}{l}\text { Cultural } \\
\text { Foresight }\end{array}$ & Scanning & Exploratory & $\begin{array}{l}\text { Signs of } \\
\text { Cultural } \\
\text { Developments }\end{array}$ & Long(er) term & $\begin{array}{l}\text { Participatory-Semi } \\
\text { automated }\end{array}$ & $\begin{array}{l}\text { Emerging } \\
\text { Cultural Issues }\end{array}$ & $\begin{array}{l}\text { Culture-center } \\
\text { ed politician } \\
\text { organization }\end{array}$ \\
\hline \begin{tabular}{|l} 
Decision \\
making and \\
cultural policy
\end{tabular} & Monitoring & Issue-centered & $\begin{array}{l}\text { Cultural } \\
\text { components } \\
\text { and indicators }\end{array}$ & Mid term & $\begin{array}{l}\text { Non } \\
\text { participatory-Semi } \\
\text { automated }\end{array}$ & $\begin{array}{l}\text { Uncertainties } \\
\text { and cultural } \\
\text { scenarios }\end{array}$ & $\begin{array}{l}\text { Culture-center } \\
\text { ed observer } \\
\text { organization }\end{array}$ \\
\hline $\begin{array}{l}\text { As part of a } \\
\text { foresight } \\
\text { cycle }\end{array}$ & & & & Short term & Combined-Manual & $\begin{array}{l}\text { Cultural } \\
\text { opportunities } \\
\text { and threats }\end{array}$ & \\
\hline \multirow[t]{2}{*}{$\begin{array}{l}\text { As an } \\
\text { independent } \\
\text { activity }\end{array}$} & & & & Multiple & & $\begin{array}{l}\text { Cultural issues } \\
\text { / problems }\end{array}$ & \\
\hline & & & & & & $\begin{array}{l}\text { Database and } \\
\text { Required } \\
\text { Reports }\end{array}$ & \\
\hline
\end{tabular}

Fig. 9. Scenario 2.2: observation morphological model based on drivers of main step parameters (monitoring)

Culture is the unique feature and strategic advantage of Islamic Republic of Iran; to this end, cultural growth and caring it is emphasized in management dialogue of Islamic Republic of Iran. Here, the important point is to utilize futures studies concepts in cultural observation activities. Cultural 
observation requires simultaneous attention to monitoring and scanning which implies "scanning cultural development signs", "identifying cultural progressing and deterring factors timely" and "monitoring cultural problems" which support "cultural foresight and policymaking". Provided scenarios in present study would aid to link "reactive and short term initiatives" and "active and long term policies" in culture by connecting scanning and monitoring in observation activities of cultural organizations; overall, observation activities would aid deep thinking on future and linking the present and future by using futures studies concepts and horizon scanning. Scanning would promote the capability of strategic thinking (Habegger, 2009) and discussions on future - oriented issues; in fact, long term identity of horizon scanning would help organization to be less reactive (Babbage, 2008). Scanning products would promote dialogues on future and help decision makers' concentration on current challenges and emerging issues (Van Der Heijden, 2011; Butter et al., 2010). On the other hand, monitoring helps decision makers to predict external changes and react rapidly (Bengston, 2013). Observation not only indicates future key issues and factors along with their potential interactions but also it can help to raise radical and key questions to adopt more robust and resilience strategy (Van Rij, 2010a).

Therefore, the value of respecting observation in organization is clear. Observation activities in cultural organizations are mainly focused on monitoring and measuring the status of cultural components and indication and cultural problems surveillance while the velocity of rapid changes, increasing the complexities and the frequency of surprises, being ready for an ambiguous future through promoting foresight insight, stimulating on how emerging issues can impact on culture future and make ready contingency plans. A well-devised observation system is needed to realize such goals. By using morphological model solution space and provided alternatives in present research, cultural organization can design a detailed observation system depended on their goals and needs through decision making on parameters and values of morphological model. The important point is transition from cultural status monitoring and reactive initiatives toward scanning and proactive initiatives.

\section{References}

Aguilar, F. J. (1967). Scanning the business environment. Macmillan.

Amanatidou, E., Butter, M., Carabias, V., Könnölä, T., Leis, M., Saritas, O., ... \& van Rij, V. (2012). On concepts and methods in horizon scanning: Lessons from initiating policy dialogues on emerging issues. Science and Public Policy, 39(2), 208-221.

Anbari, M. (2011). Cultural observatory conceptual gradual change. Tehran: Rahdan Publications.

Anonymous. (2005). Mandate of cultural observation in I. R. of Iran. Tehran: Cultural Revolution Higher Council.

Anonymous. (2013). Iranian cultural engineering map. Tehran: Cultural Revolution Higher Council Secretariat.

Azimi, E. (2011). Revising futures studies theoretical device in Islamic ideology. Researches on Futures (a series of papers), 11-42.

Babbage, R. (2008). Strategic Decision Making: Optimising Australia's National Security Planning and Coordination for 2015. Kokoda Foundation.

Bengston, D. N. (2013). Horizon scanning for environmental foresight: A review of issues and approaches. United States Department of Agriculture, Forest Service, Northern Research Station.

Bishop, P. (2009) Horizon Scanning, Why is it so hard?. Retrieved from http://www.law.uh.edu/faculty/thester/courses/Emerging\%20Tech\%202011/Horizon\%20Scanning. pdf

Choo, C. W. (2001). Environmental scanning as information seeking and organizational learning. Information Research, 7(1), 7-1.

Connery, D. (2012). Horizon Scanning: Bringing strategic insight to national security policymaking. Occasional Paper, (5). 
Cuhls, K., Erdmann, L., Warnke, P., Toivanen, H., Toivanen, M., van der Giessen, A. M., \& Seiffert, L. (2015). Models of hirizon scanning. How to integrate horizon scanning into European research and innovation policies.

Da Costa, O., Warnke, P., Cagnin, C., \& Scapolo, F. (2008). The impact of foresight on policy-making: insights from the FORLEARN mutual learning process. Technology Analysis \& Strategic Management, 20(3), 369-387.

Draeger, D. (2011). Environmental \& Horizon Scanning. Retrieved from https://aiglatsonforesight.com/2011/05/10/environmental-horizon-scanning

Eivazi, M. (2015). New emerging cultural, social and political phenomena and their roles in Iranian progress. the 4th Conference on Islamic-Iranian progress paradigm; Iranian progress: past, present and future.

Habegger, B. (2009). Horizon scanning in government: Concept, country experiences, and models for Switzerland. Center for Security Studies (CSS), ETH Zurich.

Hiltunen, E. (2008). Good sources of weak signals: a global study of where futurists look for weak signals. Journal of Futures Studies, 12(4), 21-44.

Kavoosi, A., Bigdeli, M., \& Mohammadnejad Alizamini, A. (2008). Studying how to transfer cultural activities to nongovernmental section and providing proper guidelines considering the 3rd and 4th development plans. a series of papers on cultural planning, Tehran: Strategic Research Center of Expedience Council.

Könnölä, T., Salo, A., Cagnin, C., Carabias, V., \& Vilkkumaa, E. (2012). Facing the future: Scanning, synthesizing and sense-making in horizon scanning. Science and public policy, 39(2), 222-231.

Kuosa, T. (2010). Futures signals sense-making framework (FSSF): A start-up tool to analyse and categorise weak signals, wild cards, drivers, trends and other types of information. Futures, 42(1), 42-48.

Lavoix, H. (2012). Horizon Scanning and Monitoring for Anticipation: Definition and Practice. Retrieved from https://www.redanalysis.org/2012/06/22/horizon-scanning-and-monitoring-foranticipation-definition and-practice/

Lesca, H., \& Lesca, N. (2014). Strategic decisions and weak signals: anticipation for decision-making. John Wiley \& Sons.

Lindgren, M., \& Bandfold, H. (2003). Scenario Planning: The Link between Future and Industry.

Major, E., Asch, D., \& Cordey-Hayes, M. (2001). Foresight as a core competence. Futures, 33(2), 91107.

Malekifar, E. (2007). Futures studies aliphatic. Tehran: Industry and Technology Think Tank.

Maurits Butter, M. L., Cagnin, C., Carabias, V., Könnölä, T., van Rij, V., Klerx, J., ... \& Pace, L. (2010, October). Scanning for early recognition of emerging issues; dealing with the unexpected, an operational framework for the identification and assessment of new future developments. In Workshop paper: SESTI methodology, workshop (Vol. 26).

Mendonça, S., Cardoso, G., \& Caraça, J. (2012). The strategic strength of weak signal analysis. Futures, 44(3), 218-228.

Mendonça, S., e Cunha, M. P., Ruff, F., \& Kaivo-oja, J. (2009). Venturing into the wilderness: Preparing for wild cards in the civil aircraft and asset-management industries. Long Range Planning, 42(1), 23-41.

Miles, I., \& Saritas, O. (2012). The depth of the horizon: searching, scanning and widening horizons. Foresight, 14(6), 530-545.

Moqtadaei, M. (2008). Cultural and cultural observatory, the proposal of executing cultural observatory in Isfahan. Isfahan Culture, $41 \& 42,5-16$.

Negahdary, B. (2006). Cultural observatory: dimensions and guidelines. IRIB Monthly Journal, 57, 76 $-87$.

Plebańczyk, K. (2014). The Idea of Culture Observatories-Overview. Acta Academiae Artium Vilnensis, (72).

Rashad, E. (2006). Culture engineering and cultural engineering. Cultural Engineering Biweekly, 2. 
Ritchey, T. (2002). Modelling complex socio-technical systems using morphological analysis. Adapted from an address to the Swedish Parliamentary IT Commission, Stockholm.

Ritchey, T. (2013). General Morphological Analysis, A general method for non-quantified modelling. Adapted from an address to Swedish Morphological Society: http://swemorph.com/pdf/gma.pdf

Ritchey, T. (2015). Principles of cross-consistency assessment in general morphological modelling. Acta Morphologica Generalis, 4.

Royayi, R. \& Rasooli, A. (2008). Cultural policymaking requirements in national level. a series of cultural planning articles (2), Tehran: Strategic Research Center of Expedience Council.

Salehi Amiri, R., \& Azimi Dolatabadi, A. (2008). the basics of cultural policymaking and planning. Tehran: Strategic Research Center of Expedience Council.

Saritas, O., \& Miles, I. (2012). Scan-4-Light: a Searchlight function horizon scanning and trend monitoring project. Foresight, 14(6), 489-510.

Saritas, O., \& Smith, J. E. (2011). The big picture-trends, drivers, wild cards, discontinuities and weak signals. Futures, 43(3), 292-312.

Schein, E. H. (2004). Organizational Culture and LeaderShip(3rd Edition). Jossey-Bass, a Wiley Imprint.

Shaffer, M. S. (Ed.). (2012). Public culture: Diversity, democracy, and community in the United States. University of Pennsylvania Press.

Sutherland, W. J., Bardsley, S., Bennun, L., Clout, M., Côté, I. M., Depledge, M. H., ... \& Gibbons, D. W. (2011). Horizon scan of global conservation issues for 2011. Trends in ecology \& evolution, 26(1), 10-16.

Van der Heijden, K. (2011). Scenarios: the art of strategic conversation. John Wiley \& Sons.

Van Rij, V. (2010a). Joint horizon scanning: identifying common strategic choices and questions for knowledge. Science and Public Policy, 37(1), 7-18.

Van Rij, V. (2010b). Horizon scanning: monitoring plausible and desirable futures. In Knowledge Democracy (pp. 227-240). Springer, Berlin, Heidelberg.

Van Rij, V. (2011). Wild cards as future shakers and shapers. The 4th International Seville Conference on Future-Oriented Technology Analysis. (FTA): 12 \& 13 May.

Van Rij, V. (2013). New emerging issues and wild cards as future shakers and shapers. In Recent Developments in Foresight Methodologies (pp. 67-89). Springer, Boston, MA.

Zare, B., Avarzamani, H.; and Safaei Sabet, H. (2014). Cultural challenges of the I. R. of Iran in next ten years. Public Culture, $84-86$.

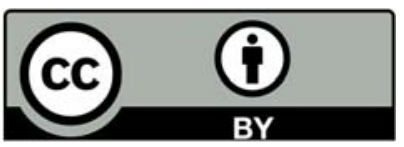

(C) 2018 by the authors; licensee Growing Science, Canada. This is an open access article distributed under the terms and conditions of the Creative Commons Attribution (CC-BY) license (http://creativecommons.org/licenses/by/4.0/). 